\title{
El patrimonio cultural desde las voces de los jóvenes. Un punto de partida para la educación patrimonial
}

\author{
The cultural heritage in the voice of young people. \\ A starting point for heritage education
}

ISSN 1510-2432 - ISSN 1688-9304 (en línea) - DOI: http://dx.doi.org/10.18861/cied.2015.6.2.36

\begin{abstract}
Adriana Careaga
Master en Políticas Públicas, Universidad ORT Uruguay. Licenciada en Educación, Universidad Católica del Uruguay. Profesora de Educación Media Especialidad Historia, Instituto de Profesores Artigas. Directora Espacio Cultural "Al pie de la muralla", declarado de interés ministerial y municipal. Coordinadora Programa Educativo "Diálogos con la historia" orientado a la Educación en el Patrimonio. Consultora internacional de educación.
\end{abstract}

Fecha de recibido: 09/04/2015

Fecha de aceptado: 29/05/2015

\section{Resumen}

Esta investigación tiene como principal objetivo indagar acerca de las concepciones sobre patrimonio cultural que tienen los adolescentes del primer ciclo de enseñanza media a partir de una experiencia de una propuesta didáctica basada en el aprendizaje experiencial denominada "Tras la muralla perdida" que comprende un recorrido por los restos de fortificaciones coloniales con un taller musical. Se realizó en un espacio cultural, ámbito de educación no formal que promueve la educación patrimonial, situado en el casco histórico de la capital del país durante los años 2013 y 2014. Se analizaron los productos logrados en el taller en forma de décimas poéticas improvisadas con acompañamiento musical, así como también los testimonios escritos que, de forma voluntaria, dejaron en la pizarra al culminar el paseo y las observaciones realizadas por el investigador.

El interés de la investigación se centró en dilucidar qué piensan los jóvenes acerca del patrimonio cultural y su relación con la ciudad en la que habitan, perspectiva poco explorada en la educación escolar formal.

De esta manera, primero se abordan las principales nociones teóricas acerca del patrimonio cultural y sus alcances en la educación. Luego se presenta el detalle del recorrido, prestando especial atención al proceso de construcción de las décimas poéticas objeto de este estudio y procediendo a su análisis y categorización. Finalmente se establecen algunas conclusiones acerca de la importancia del lugar que debe ocupar la educación patrimonial para lograr conformar una ciudadanía crítica, activa y democrática.

Palabras clave: patrimonio cultural, aprendizaje experiencial, percepciones juveniles, educación patrimonial

\begin{abstract}
This research has as main objective to inquire about the concepts of cultural heritage in the young adolescents of the first cycle of Secondary Education from an educative proposal based on experiential learning called "After the lost wall" that includes a tour by the remnants of colonial fortifications with a musical workshop. The research was carried out during the years 2013 and 2014 in a cultural space of non-formal education located in the historic center of the capital that promotes heritage education. The workshop results, under the form of improvised poetry- with musical accompaniment are analyzed as well
\end{abstract}


as written testimony voluntarily left on the board after the walk and observations made by the researcher.

The interest of the research focused on elucidating the perceptions of young people about the cultural heritage and its relationship with the city in which they live, an unexplored approach in formal education.

It presents the main theoretical notions of cultural heritage and achievements in education as well as a detailed route, paying special attention to the construction process of décima verses object of this study that are analyzed and categorized. Finally, conclusions are drawn about the importance of the right place of heritage education for society to become actively democratic and critical.

Key words: heritage, experiential learning, youth perceptions, heritage education

\section{Antecedentes conceptuales y problemática de estudio. Los diversos significados del patrimonio cultural}

Hablar de patrimonio en el siglo XXI parecería un asunto acordado, laudado y hasta diríamos "sacralizado". Sin embargo, esta visión de hoy, dinámica con respecto a los objetos a "patrimonializar", ha cambiado con respecto a la inmutabilidad característica del siglo XIX, no solo en cuanto a los valores a otorgar sino a las formas que revisten esos objetos. La monumentalidad decimonónica traducida en elementos materiales ha dejado lugar a otro tipo de valoración, más abarcativa hacia lo inmaterial -como las tradiciones y los usos de las comunidades- y más acorde con los tiempos que corren. El patrimonio brinda tributo al período histórico que devela, por tanto cada sociedad decide de acuerdo a su tiempo y circunstancias cuáles son los bienes tanto materiales como inmateriales a ser rescatados del olvido y a ser integrados en la memoria colectiva.

Empero, el concepto de patrimonio constituye un imán semántico que acoge una diversidad de significados: memoria, identidad, historia, valor, legado, uso y tradición, entre otros. Quizá la definición más común de patrimonio cultural en los imaginarios sociales es todo aquello heredado de los padres.

Se ha observado una expansión de la noción de patrimonio cultural desde una primera modernidad que lo circunscribía a los espacios de los museos, a determinadas leyes y al juicio solo de expertos. En cambio, en una segunda modernidad se advierte una patrimonialización de la cultura, determinada en cierta forma por una expansión ilimitada del repertorio patrimonial y una proliferación de sujetos que lo activan, que convergen en una suerte de "movimiento cívico" y ya no exclusivo de las élites.

Luego de las dos guerras mundiales, y con una mirada eurocéntrica, la sociedad expresa un marcado interés por la defensa de sus manifestaciones culturales, lo que se evidencia en diversos documentos y cartas internacionales. Tal es el caso de la Carta de Atenas (1931), la Convención de la Haya (1954) y la Convención de Unesco de 1972, que reconocen el aspecto cultural del patrimonio dando cabida a todas aquellas manifestaciones culturales de los pueblos, incluido el patrimonio natural en cuyo marco se han desarrollado. Específicamente, la Convención de Unesco de 1972 sobre la protección del patrimonio mundial, cultural y natural considera que el patrimonio está integrado por:

1. Los monumentos: obras arquitectónicas, de escultura o de pintura monumentales, elementos o estructuras de carácter arqueológico, inscripciones, cavernas y grupos de elementos, que tengan un valor universal excepcional desde el punto de vista de la historia, del arte o de la ciencia, 
2. Los conjuntos: grupos de construcciones, aisladas o reunidas, cuya arquitectura, unidad e integración en el paisaje les dé un valor universal excepcional desde el punto de vista de la historia, del arte o de la ciencia,

3. Los lugares: obras del hombre u obras conjuntas del hombre y la naturaleza así como las zonas, incluidos los lugares arqueológicos que tengan un valor universal excepcional desde el punto de vista histórico, estético, etnológico o antropológico.

Esta Convención de 1972 supuso nuevas conceptualizaciones emanadas de las ciencias sociales -especialmente la antropología- que se refuerzan hacia 1989 con la Recomendación sobre la Salvaguardia de la Cultura Tradicional y Popular que determina la importancia de las creaciones identitarias de las comunidades, fundadas en la tradición ya sean lenguas, literatura, música, danza, juegos, arquitectura, fiestas y oficios, entre otras. Posteriormente, y a partir de renovadas teorías y conceptualizaciones, surgen otras convenciones internacionales que de alguna manera marcan un quiebre con el paradigma anterior (Convención para la Salvaguardia del Patrimonio Cultural Inmaterial de 2003 y para la Protección y Promoción de la Diversidad de las Expresiones Culturales de 2005, como también declaraciones de Icomos como la Carta de Burra, adoptada en el año 1979 y cuya última actualización fue en 1999, entre otros).

En este sentido, el concepto de patrimonio evidencia procesos constantes de deconstrucción y construcción sin llegar a constituirse en un dispositivo para conocer o hacer historia. El valor es otorgado desde la interpelación que desde el presente se le realiza a ese pasado escogido (Hernández, 2003).

Desde esta perspectiva podríamos sostener que el patrimonio en este constante proceso presenta diferentes valores. El primero sería el de uso que atiende a la utilidad que presenta el objeto. Un segundo valor sería formal, tomando en consideración la atracción que debe despertar a los sentidos en lo atinente a su forma, al tamaño, al color. Y un último valor, el simbólico, que está dado por constituir testimonio de hechos o situaciones pasadas que tienden puentes hacia el presente.

En el momento en el que estos diferentes valores confluyen y se asocian a una determinada identidad, valores o ideas, esos objetos patrimoniales entran en la categoría de "sacros", convirtiéndose así en inmutables. En cierta forma también devienen en símbolos que provocan emoción. Aquí hay dos dimensiones que convergen y, a su vez, se retroalimentan: la dimensión de valor y la de activación. Para que un objeto patrimonial se convierta en tal, primero se le otorga valor y luego se activa a través de los relatos identitarios construidos en base a un saber científico (Prats, 1997). De tal forma, la selección de los objetos patrimoniales pasible de jerarquización no es, aunque lo parezca, ni aséptica, ni neutral ni objetiva, sino que está imbuida de valores que responden a una determinada historicidad reconocida por la comunidad como relevante de su pasado y de su cultura.

A su vez, el elemento patrimonial "activado" puede convertirse en un elemento de la conciencia personal que puede generar relaciones simbólicas y significativas con unos objetos y unos lugares (González Monfort, 2006). 
Según Fontal Merillas O. (2004) existiría un conjunto de bases conceptuales del patrimonio que serían las siguientes:

- Se presenta en un soporte material, inmaterial y espiritual.

- Está sujeto a la atribución de valores.

- Define y caracteriza a individuos y culturas (define identidades).

- Caracteriza contextos.

- Se transmite generacionalmente.

Todo lo anterior se daría en un escenario no exento de conflictos y disputas por el poder, puesto que no existe una homogeneidad de actores en la sociedad ni una convergencia de intereses entre ello. (Mançano, 2005). Muy por el contrario, el patrimonio cultural admite variadas y múltiples miradas y abordajes que podrían resumirse en la siguiente imagen:

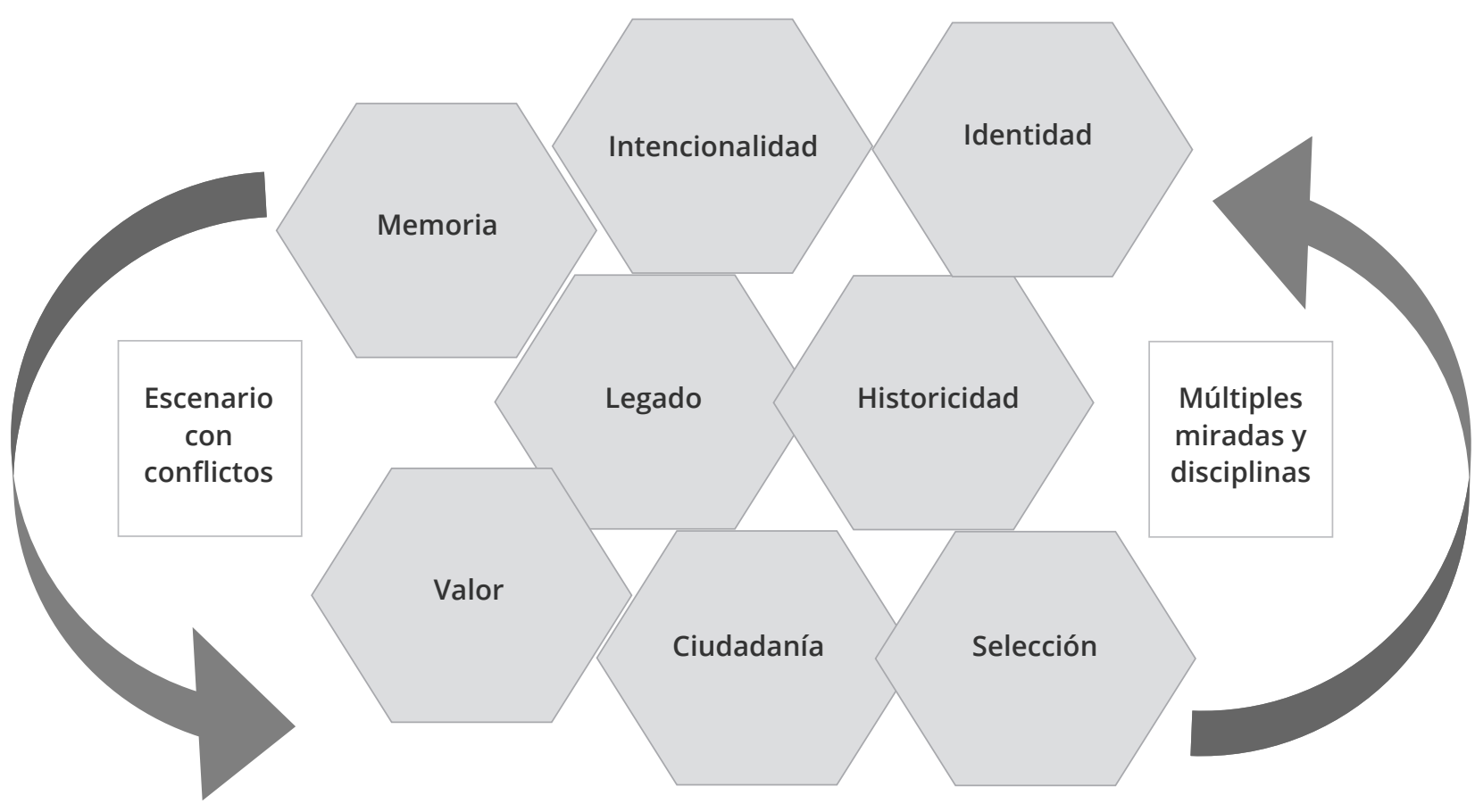

Figura 1. El entramado patrimonial

Una de las claves para comprender al patrimonio es como construcción social bajo una determinada historicidad donde los objetos no están naturalmente dados a la sociedad sino que es ella en su conjunto (lo que sería lo más deseable) o un grupo de personas, quienes seleccionan y deciden cuáles son los objetos que deben perdurar en la memoria colectiva. Los objetos no se constituyen en patrimonio per se sino que son los sujetos quienes les otorgan su "patrimonialidad" (Tugores y Planas, 2006; Ballart y Juan, 2010). Todo ello en un proceso no exento de conflictividad, de choque de intereses. En otras palabras, no hay una naturalización del patrimonio ni un mandato del pasado. En tal sentido, toda historia es historia contemporánea (Carr, 1984). Es el presente el que interpela al pasado para preservarlo. De ahí que cada tiempo histórico ha guardado, ignorado y/o descuidado sus objetos patrimonializables según sus necesidades y sus concepciones. 


\section{Educar en patrimonio}

Ya desde fines del siglo XX la Unesco define a la educación en una perspectiva amplia, como un proceso a lo largo de toda la vida y un instrumento que permitirá alcanzar los ideales de paz, libertad y justicia social a través del cual los ciudadanos aprendan a través del diálogo a vivir con sus diferencias (Delors, 1999).

La educación en patrimonio, o educación patrimonial, adquiere importancia como anclaje en una época en la que conviven una sociedad marcada por lo inmediato, lo presente, lo efímero que gira en torno al espacio y la dimensión individual insertos en una dinámica global (Lipovetsky, 1996) y la reivindicación de lo local con una reafirmación de las identidades.

La educación patrimonial se podría definir como "el proceso pedagógico centrado en las percepciones, conocimientos y valores que subyacen en una sociedad. De esta manera, el bien patrimonial se convierte en un recurso para el aprendizaje, capaz de conectar al ciudadano con su diversidad cultural y su entorno social" (García Valecillo, 2009). De esta forma, el diseño de programas y acciones de educación tendrán como centro a las personas y no al bien cultural, trabajando en torno a los valores culturales próximos a ellas para llegar así a los valores universales.

García Valecillo (2009) plantea cuatro dimensiones pedagógicas, entendidas como espacios de referencia para la sistematización de los contenidos y estrategias educativos según los escenarios a implementar que estarían actuando de forma transversal a aquellas y al propio proceso educativo. Las cuatro dimensiones pedagógicas serían i) conocer, ii) comprender, iii) valorar y iv) actuar, que a su vez se correlacionan con los pilares de la educación propuestos por Unesco: i) conocer, ii) hacer, iii) vivir juntos y iv) ser (Delors, 1999). A su vez, dimensiones y pilares se retroalimentan a partir de las experiencias de los participantes generadas fundamentalmente a través de un aprendizaje dialógico entre ellos.

i) La primera dimensión, la de conocer, pretende generar procesos de aprendizaje basados en los conocimientos del patrimonio cultural, que irían desde los científico académicos hasta las vivencias y conocimientos populares. Será necesario un abordaje integral, desde varias disciplinas que permitan generar aprendizajes significativos.

ii) La segunda dimensión, la de comprender, pone su énfasis en los usos, significados y dinámicas sociales que denotan los bienes patrimoniales en una comunidad. De esta forma la praxis educativa debería orientarse a ayudar a los aprendices a develar las tramas sociales que ha mantenido el patrimonio a lo largo de la historia.

iii) La dimensión del valorar consistiría en ayudar a conformar una ciudadanía responsable con los bienes culturales en lo relativo a su sustentabilidad. Las actividades educativas deberían estar centradas tanto en visualizar posibles caminos de una gestión ciudadana participativa como en identificar y desarrollar las competencias necesarias para llevarla a cabo.

iv) La cuarta dimensión, la de actuar, significa poder desarrollar las competencias requeridas para una gestión patrimonial a los efectos de intervenir individual o colectivamente en la preservación de los bienes patrimoniales. Esto se traduce en acciones específicas de capacitación en destrezas u oficios, en cualquiera de los ámbitos de actuación, formal, informal o no formal. 
En suma, la educación patrimonial consistiría en un proceso educativo permanente y sistemático, centrado en el patrimonio como fuente primaria de conocimiento y enriquecimiento individual y colectivo a la vez que actúa como instrumento de "alfabetización cultural" que permite a la persona interpretar el mundo que le rodea y guiar sus intervenciones (Texeira en Cantón Arjona, 2009).

Uno de los puntos problemáticos del abordaje del patrimonio cultural desde la enseñanza es que bajo su aparente objetividad se activa más comúnmente el factor emocional por sobre el cognitivo, sin que exista un planteo complejo acerca del carácter de la diversidad de los patrimonios, de la selección de los bienes patrimoniales o de los actores que efectuaron dicha selección. Estos aspectos resultan básicos aunque poco transitados en la educación formal.

Si bien se cuenta con fuentes conceptuales en el plano internacional, a nivel nacional existen escasos enfoques -especialmente desde la formación de formadores- que posibiliten la comprensión de la complejidad del tema patrimonial. Esto dificultaría en cierta forma su enseñanza a las jóvenes generaciones. No obstante ello, podemos mencionar a nivel internacional algunos materiales didácticos como el Manual de Unesco Patrimonio Mundial en Mano de Jóvenes - Paquete de Materiales Didácticos para Docentes (2005) y la serie didáctica del Museo de Antropología de Córdoba, Argentina, que producen contenidos y actividades didácticos para educar en patrimonio, educar en valores e interpretar el patrimonio en el aula. Con respecto al campo de la investigación cabe mencionar el trabajo de Giacomasso et al. (2014) “Jóvenes resignificando patrimonios. Análisis de una experiencia escolar en la ciudad de Olavarría".

Indagar en las percepciones de los jóvenes acerca del patrimonio permitiría en cierta forma seguir profundizando en los sustentos teóricos y las formas de enseñarlo.

\section{Metodología}

En esta investigación utilizamos un enfoque cualitativo ya que nos interesaba comprender el significado que los jóvenes, desde su mundo, otorgan al patrimonio y a sus experiencias en el mismo a través de un recorrido didáctico (Merriam, 1998:6).

De esta forma se pretendió comprender el fenómeno desde sus diversas perspectivas focalizándose en el aspecto etnográfico a alcanzar “...valiosos datos descriptivos de los contextos, actividades y creencias de los participantes en los escenarios educativos [...] tal como estos ocurren naturalmente" (Goetz \& LeCompte, 2010:41). En este caso particular se indagó en un contexto de educación no formal como lo constituye la oferta que presenta un espacio cultural en el marco de una salida didáctica organizada en conjunto con la institución educativa.

Como no se pretende generalizar los hallazgos sino analizarlos y comprenderlos en su contexto, por una parte se investigó el fenómeno en el marco de su realidad (Yin, 2003). Por otra parte, se eligió un estudio de casos de tipo múltiple (Stake, 1999), en el cual el universo de estudio estuvo constituido por trece producciones correspondientes a trece grupos de estudiantes (2. ${ }^{\circ}$ año del Ciclo Básico de Enseñanza Secundaria), tomando a cada producción grupal como un caso en sí mismo. Los criterios de selección de la muestra fueron intencionales, basados en las siguientes características socio-estructurales: i) jóvenes adolescentes cursando $2 .^{\circ}$ año de Enseñanza Secundaria; ii) asistentes a instituciones educativas; iii) de la capital del país. 
Para analizar las percepciones de los jóvenes adolescentes de 13 años se analizaron las producciones colectivas acerca de la visión del patrimonio recurriendo a estrofas en forma de décimas, especialmente significativas en la poesía popular y rural rioplatense, creación de los estudiantes durante los años 2013 y 2014 como producto de un recorrido didáctico denominado "Tras la muralla perdida", ofrecido por un espacio cultural en el casco histórico de la capital del país. El estudio se centra específicamente en el análisis del discurso a partir de los conceptos allí vertidos. A posteriori se procedió a una categorización semántica y conceptual vinculada con el marco teórico que da sustento al trabajo.

Para asegurar la validez y confiabilidad de los datos obtenidos se recurrió a la triangulación hermenéutica cruzándose de forma dialéctica toda la información surgida de los instrumentos utilizados (Cisterna Cabrera, 2005). Para ello, en primer lugar, se triangularon intracasos en base a las tres fuentes primarias de datos: i) las producciones colectivas o décimas, ii) los testimonios voluntarios escritos en el pizarrón, y iii) la observación no participante del investigador. En segundo lugar, se procedió a una triangulación de intercasos que permitió vislumbrar similitudes entre ellos. Estos dos niveles posibilitaron el análisis y la comprensión de la multiplicidad de datos recogidos así la realización de un control en la interpretación y reinterpretación de los mismos (Cook y Reichardt, 1995).

\section{La propuesta didáctica "Tras la muralla perdida"}

"Tras la muralla perdida" es una propuesta didáctica con formato de recorrido que aborda el patrimonio cultural desde los vestigios materiales de la antigua muralla de Montevideo para ir construyendo una trama de conocimientos, significados, percepciones y emociones acerca de la vida en la colonia.

El recorrido por las huellas de las fortificaciones busca involucrar al estudiante en el pasado de la ciudad y, a su vez, relacionarlo con su presente y proyectarlo hacia el futuro, apelando a la construcción de una ciudadanía activa y crítica en la conservación de su patrimonio. La ciudad se torna de esta forma en un todo, en una ciudad educadora por excelencia que promueve "aventuras intelectuales" de aprendizaje (Asensio y Pol, 2002).

La visita se concibe como una continuidad entre la preparación, el recorrido en sí mismo y las actividades posteriores que se desarrollen en el aula en clave de "visita expandida", que tiende puentes entre el aula y el espacio cultural. El profesor contará así con materiales de apoyo que le permitirán optimizar al máximo este recorrido didáctico para lograr en los estudiantes un aprendizaje significativo en sus trayectorias educativas (Alderoqui, 2006).

Asimismo se les brinda al comienzo del recorrido un mapa para que consignen el camino transitado, así como preguntas orientadoras para que los jóvenes sean capaces de develar "los restos del tiempo incrustados en el paisaje urbano" que la ciudad ofrece para reconectar con su historia (Hayden, 1997).

En determinados momentos del recorrido se recurre a animadores sociales que apuntan al elemento emocional para conceptualizar hechos históricos basándose en la técnica de la recreación histórica, que no es una mera dramatización sino que se enfoca a desarrollar una forma vivencial del aprendizaje de la historia que apunta a crear una comprensión empática, el sentimiento de "estar allí". Al final del recorrido se realiza un taller para la construcción de una décima poético-musical que dé cuenta del recorrido y de la visión que los participantes tienen acerca del patrimonio. Es en este punto específico que se centra la presente investigación. 
La propuesta es integral ya que aborda el patrimonio cultural desde las sensaciones, las emociones y las percepciones. El modelo de aprendizaje se basa en la construcción activa del conocimiento del patrimonio. El mismo está enfocado en la comprensión e interpretación desde una perspectiva del aprendizaje situado en un contexto real de forma dialógica.

\section{La ciudad y el territorio ¿Cómo se piensan los bienes que pueden ser patrimoniales?}

"Las ciudades son un conjunto de muchas cosas: memorias, deseos, signos de un lenguaje; son lugares de trueque, como explican todos los libros de historia de la economía, pero estos truques no lo son sólo de mercancías, son también trueques de palabras, de deseos, de recuerdos"

Calvino (2013)

El territorio que se recorre son ocho calles en el extremo este del casco antiguo montevideano. A lo largo de este recorrido se encuentra el entramado diverso del centro histórico: oficinas, bancos, museos, escuelas, Casa de Gobierno, así como también tugurizaciones y aspectos tales como ausencia de cartelería orientadora, entre otros. Esto lleva a repensar de qué forma un territorio se puede patrimonializar desde el conjunto de voluntades colectivas, es decir, desde una construcción social pero a la vez individual en clave de conciencia cívica. En este sentido, existe un apoyo desde la órbita pública -alcaldías y diferentes ministerios- a través de la continua limpieza, la vigilancia de la policía turística o la instalación de cámaras de seguridad en la totalidad de las cien manzanas del casco histórico.

El recorrido didáctico está basado en el aprendizaje experiencial, y se asume que el conocimiento se crea a través de la transformación provocada por la experiencia (Kolb, 1984). Se pretende, de tal forma, ayudar a los jóvenes a pensar y repensar esta franja de territorio urbano como una suerte de palimpsesto, aquel antiguo documento que se reinscribía constantemente en las diversas épocas históricas, por estar en permanente cambio afectado tanto por procesos "naturales" como sociales (Corboz, 2001).

Asimismo se apoya en el enfoque del aprendizaje en el que se concibe al conocimiento como parte y producto de la actividad, el contexto y la cultura en que se desarrolla y utiliza (Díaz Barriga, 2003).

\section{Análisis e interpretación de los resultados}

De acuerdo al objetivo planteado en la investigación y a las concepciones teóricas que le dan sustento, se analizaron e interpretaron los datos obtenidos a partir del análisis documental de las décimas, de lo consignado en el pizarrón y de las observaciones.

Dado el carácter intencional de la muestra en base a criterios previamente definidos, se procedió en primera instancia a describir y caracterizar los casos y se elaboró una matriz general. Seis de los trece grupos provenían de instituciones privadas y siete de instituciones públicas. Los grupos tienen un promedio de 35 estudiantes: 18 estudiantes el grupo más pequeño y 47 el más numeroso, tal como se observa en la matriz que se detalla a continuación: 
Cuadro 1. Mapeo de singularidad de los casos

\begin{tabular}{|c|c|c|c|}
\hline Producción/Décima & Institución & Contexto social & $\begin{array}{c}\text { Cantidad de } \\
\text { estudiantes }\end{array}$ \\
\hline A & Privada & Medio & 35 \\
\hline B & Pública & Medio & 42 \\
\hline C & Pública & Bajo & 34 \\
\hline D & Pública & Bajo & 32 \\
\hline E & Privada & Alto & 38 \\
\hline F & Pública & Crítico & 18 \\
\hline G & Privada & Alto & 35 \\
\hline H & Pública & Crítico & 47 \\
\hline I & Privada & Medio & 27 \\
\hline J & Pública & Medio & 45 \\
\hline K & Privada & Medio & 34 \\
\hline L & Privada & Medio & 31 \\
\hline M & Pública & Bajo & 42 \\
\hline
\end{tabular}

\section{A) Análisis de las décimas}

Una vez analizadas las trece décimas de forma individual se dividieron las respuestas de las percepciones de los jóvenes en categorías descriptivas para luego establecer subcategorías emergentes. Estas categorías y subcategorías fueron posteriormente procesadas de acuerdo a sus frecuencias. Asimismo se compararon los grupos de de instituciones públicas y los de instituciones privadas. De las percepciones de los jóvenes surgen seis categorías, cinco de las cuales se refieren directamente al patrimonio cultural y una sexta a la forma en que se realizó el aprendizaje. Dichas categorías son las siguientes: 1) Aprendizaje en contexto no formal; 2) La historia como fuente de conocimiento patrimonial; 3) Puesta en valor del objeto patrimonial; 4) Jerarquización de objetos patrimoniales; 5) Memoria; y 6) Identidad.

El detalle de las mismas con sus frecuencias y la procedencia según ámbito público o privado se presenta en el siguiente cuadro. 
Cuadro 2. Categorías y subcategorías y frecuencias

\begin{tabular}{|c|c|c|c|c|}
\hline CATEGORIAS & SUBCATEGORIAS & Frecuencia & Público & Privado \\
\hline \multirow{10}{*}{$\begin{array}{l}\text { Aprendizaje en } \\
\text { contexto no } \\
\text { formal }\end{array}$} & Aprendizaje experiencial o & 8 & B & A \\
\hline & & & C & E \\
\hline & & & $\mathrm{H}$ & G \\
\hline & & & & I \\
\hline & & & & K \\
\hline & $\begin{array}{c}\text { La recreación como abordaje } \\
\text { alternativo de los acontecimientos } \\
\text { históricos }\end{array}$ & 4 & $\begin{array}{l}\mathrm{C} \\
\mathrm{F}\end{array}$ & I \\
\hline & $\begin{array}{l}\text { Satisfacción en el aprendizaje de } \\
\text { forma alternativa de la historia }\end{array}$ & 5 & & \\
\hline & & & $\mathrm{F}$ & G \\
\hline & & & & K \\
\hline & $\begin{array}{l}\text { Identificación de elementos del } \\
\text { territorio (pinturas a cielo abierto) }\end{array}$ & 1 & C & \\
\hline \multirow{8}{*}{$\begin{array}{l}\text { La historia } \\
\text { como } \\
\text { fuente de } \\
\text { conocimiento } \\
\text { patrimonial }\end{array}$} & $\begin{array}{l}\text { Identificación de diferentes } \\
\text { épocas históricas }\end{array}$ & 2 & B & \\
\hline & & & $\mathrm{I}$ & \\
\hline & Conexión entre pasado y presente & 5 & D & G \\
\hline & & & $\mathrm{H}$ & 1 \\
\hline & & & M & \\
\hline & Mirada "romántica" de la historia & 4 & D & L \\
\hline & & & G & \\
\hline & & & M & \\
\hline \multirow{5}{*}{$\begin{array}{c}\text { Puesta } \\
\text { en valor } \\
\text { del objeto } \\
\text { patrimonial }\end{array}$} & Recuperación y valorización & 7 & B & A \\
\hline & & & D & $\mathrm{E}$ \\
\hline & & & J & L \\
\hline & & & $\mathrm{M}$ & \\
\hline & Cambios que sufre el objeto & 1 & & A \\
\hline $\begin{array}{l}\text { Jerarquización } \\
\text { de objetos } \\
\text { patrimoniales }\end{array}$ & Selección intencional & 2 & $\begin{array}{l}B \\
J\end{array}$ & \\
\hline \multirow[t]{3}{*}{ Memoria } & Pilar fundamental del patrimonio & 2 & B & \\
\hline & & & J & \\
\hline & $\begin{array}{c}\text { Confusión entre memoria e } \\
\text { historia }\end{array}$ & 1 & $F$ & \\
\hline \multirow[t]{3}{*}{ Identidad } & $\begin{array}{l}\text { Identificación de aspectos } \\
\text { identitarios de la sociedad }\end{array}$ & 3 & $\mathrm{M}$ & \\
\hline & & & $C$ & \\
\hline & & & $F$ & \\
\hline
\end{tabular}




\section{Aprendizaje en contexto no formal}

En ocho de las trece décimas analizadas aparece con fuerza la importancia del aprendizaje experiencial en el abordaje del patrimonio. Cinco de las mismas pertenecen a instituciones privadas y tres a públicas. Se mencionan los sentidos puestos al servicio del aprendizaje además de los aspectos cognitivos.

"Con nuestros ojos perdidos

al horizonte lejano

con nuestra cámara en mano

hicimos un recorrido.

Con la historia en el oído

y recordando el pasado

con la muralla al costado

enriquece el panorama

y perdura en nuestro lado" (Décima E)

También se mencionan los aspectos cognitivos ligados al aprendizaje adquirido:

“Desde el liceo he partido

a la muralla perdida

luego de gran recorrida

el muro he conocido" (Décima K)

“Hoy viajé en la Ciudad vieja

aprendimos cosas nuevas

seguimos todas las huellas

buscando moralejas" (Décima G)

Se valora en cuatro décimas la recreación como abordaje alternativo de los conceptos históricos. En este caso provienen de dos instituciones públicas y dos privadas.

"Vimos expulsar a un cura

pa' fuera de la ciudad

por defender la libertad

ilustrados y valientes" (Décima C)

“La expulsión del franciscano

esclavos, gallegos y tanos

pidiendo misericordia" (Décima F)

"Como dijo un pregonero

mientras limpiaba un cañón

muy cerquita del portón

donde duerme el carcelero" (Décima I) 
"Qué bonito lo vivido

a los monjes han echado

y murales han pintado

sobre nuestro patrimonio

que con varios testimonios

Montevideo ha creado" (Décima K)

Si bien todas estas décimas aluden al episodio central de la expulsión de los curas franciscanos durante la revolución de 1815, una establece una relación específica con documentos de la época (Décima C), otra refiere a la heterogeneidad de la población en la época colonial (Décima F) y otra identifica claramente el portón de entrada a la ciudad que comúnmente se confunde con los restos de la Puerta de la Ciudadela (Décima I).

En cinco de trece décimas aparece con claridad la satisfacción por el aprendizaje, aspecto un tanto inusual por tratarse de adolescentes -con todas las características que ello supone-. De todas maneras afirman: "Y nos vamos muy sonrientes por nuestra Banda Oriental" (Décima C).

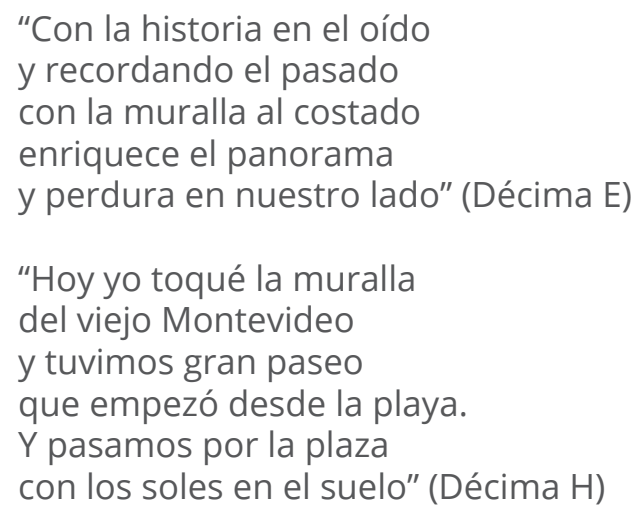

Asimismo, en dos décimas se mencionan elementos identitarios actuales de la trama urbana: los soles en el pavimento como tributo a figuras destacadas (Décima H) y los murales de Torres García a cielo abierto (Décima K).

\section{La historia como fuente de conocimiento patrimonial}

En dos décimas se advierte un aspecto clave en la enseñanza de la historia: la identificación de las diferentes épocas históricas. Ambas décimas provienen de estudiantes de instituciones públicas. Este eje temporal es uno de los vectores de la historia así como lo es el espacio, y a la vez ambos aspectos son necesarios para el abordaje del patrimonio cultural.

En las dos décimas siguientes se advierten ambos elementos puesto que se menciona el cambio del territorio y de los usos que de él se han hecho en las diferentes épocas históricas:

"También hubiera querido

darme un bañito en la playa

quién sabe si antes haya...

pasado un barco negrero" (Décima I)

"Mirando la muralla donde antes hubo playa" (Décima B) 
La conexión que el estudiante pueda realizar entre los diferentes conceptos y épocas históricas -en lo que Braudel (1968) Ilama "las líneas de mediana y larga duración"- es vital para que se produzca un aprendizaje perdurable. Este aspecto se percibe en cinco décimas, lo que representa algo menos de la mitad.

"Y a pesar del tiempo siguen

los secretos del pasado

porque aún sigue ligado

a un presente que pervive" (Décima D)

Asimismo, en cuatro décimas se advirtió una mirada acrítica y en cierta forma "romántica" de la historia, de un "pasado glorioso" o "una historia que no miente" (Décima D) que no permitiría adentrarse en la complejidad del campo epistemológico de la disciplina."

\section{Puesta en valor del objeto patrimonial}

Siete décimas manifiestan la importancia de la puesta en valor del objeto patrimonial, aspecto necesario para la conservación del patrimonio.

"La gente no se olvida de aquella historia perdida" (Décima A)

"Tu muralla despareja

nos permite recordar

que este es un lindo lugar

donde está nuestro pasado" (Décima L)

Esta puesta en valor no está exenta de emociones y sentimiento de orgullo, tal como lo muestran las siguientes dos décimas provenientes de alumnos de una institución pública y una privada:
“Mi querida Ciudad Vieja
que tantas historias has tenido
hoy simplemente te pido
que nos des tu moraleja" (Décima L)
“Nuestro orgullo dignifica
Con su historia nos quedamos" (Décima J)

Una décima alude específicamente a los cambios que se pueden producir en el objeto patrimonial según las diversas épocas históricas:

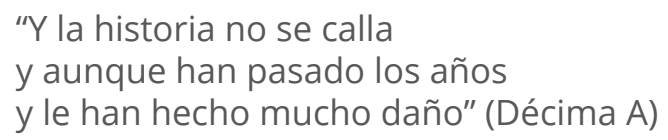

"Y la historia no se calla

y aunque han pasado los años

y le han hecho mucho daño" (Décima A)

\section{Jerarquización de objetos patrimoniales}

Para comprender el valor del objeto patrimonial es necesario realizar una posterior jerarquización de los mismos. Este aspecto aparece mencionado en dos de las trece décimas. 
“Donde antes hubo gloria

ahora queda el recuerdo

y nos pusimos de acuerdo

para que quede en la memoria" (Décima B)

"Nuestro orgullo dignifica

con su historia nos quedamos" (Décima J)

\section{Memoria}

La memoria es un elemento que contribuye a la comprensión del patrimonio y ayuda a acercarse a su complejidad. Así aparece en las mismas décimas anteriores, provenientes de instituciones públicas y que jerarquizaban el objeto patrimonial.

“Que no quede en el olvido

la memoria del pasado

algunos la han descartado" (Décima J)

Sin embargo memoria e historia no son términos intercambiables sino que ambas se refieren a ámbitos epistemológicos diferentes aunque complementarios. La memoria presenta una fragilidad a la hora de la objetividad de los hechos por ser susceptible de manipulación: "La memoria es siempre un fenómeno colectivo, aunque sea psicológicamente vivida como individual. Por el contrario, la historia es una construcción siempre problemática e incompleta de aquello que ha dejado de existir, pero que dejó rastros" (Corradini, 2006).

Comprender la diferencia entre ambos conceptos es tarea del docente para promover el aprendizaje histórico y patrimonial así como para orientar la construcción de procesos cívicos tanto individuales como colectivos.

Particularmente una décima presenta esta confusión entre ambos términos:

"Conociendo nuestra historia

nostalgiando en la memoria" (Décima F)

\section{Identidad}

Una última categoría analizada fue la identidad, y que aparece mencionada en tres de las trece décimas:

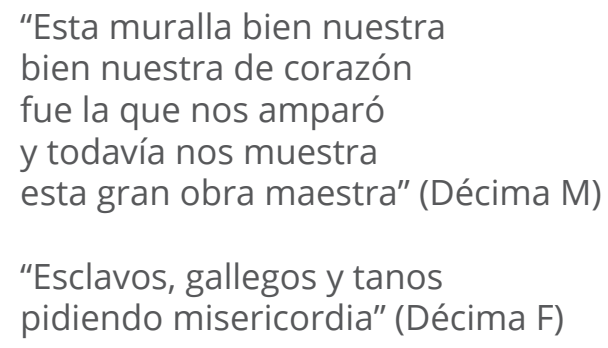

Se advierte, sin embargo, un abordaje sin complejidades al no pensar los conflictos que pudieron haber existido en épocas históricas relacionados al objeto patrimonial, en este caso concreto, la antigua muralla colonial. 


\section{B) Manifestaciones espontáneas en la pizarra}

A partir de las manifestaciones que los estudiantes plasmaron en el pizarrón al finalizar la actividad, se observó una total conformidad con la actividad y con el aprendizaje realizado. Expresiones como "Me encanta la historia", "Fue el mejor paseo de mi vida", "Vuelvo con mis padres el Día del Patrimonio" resultan por demás elocuentes acerca de la experiencia de aprendizaje vivida con placer.

Es de desatacar que, al tratarse de manifestaciones voluntarias, solo tres o cuatro estudiantes de cada grupo plasmaron sus expresiones en la pizarra. No obstante ello, ningún testimonio resultó de tenor negativo.

\section{C) Observaciones no participantes}

Durante todo el proceso de construcción de las trece décimas analizadas se realizaron observaciones teniendo en cuenta tres aspectos fundamentales:

Tiempo de producción

Disposición para la actividad por parte del grupo

Participación

Con respecto al primer aspecto, de acuerdo a estos criterios se pudo observar que no hubo grandes diferencias entre los grupos con respecto a los tiempos de producción de las décimas. El promedio fue de 20 minutos con un insumo mínimo de 16 minutos y uno máximo de 25.

El segundo aspecto a considerar fue el de la disposición para la actividad. Aquí se observaron pequeñas diferencias: algunos grupos se mostraron activos desde el comienzo. A otros les llevó un tiempo mayor culminar la actividad, para los cuales se requirió una intervención mayor por parte de los talleristas encargados de la actividad.

En un determinado grupo, esta disposición para el trabajo tomó un giro determinado, lo que implicó que les insumiera 25 minutos culminar la actividad. Esto llevó a pensar, tanto los talleristas como a la docente encargada del grupo, que esos estudiantes no estaban interesados en la actividad. A los pocos días la misma docente solicitó realizar un segundo recorrido con otro grupo, puesto que los estudiantes del primero habían contado a sus compañeros lo bueno que había resultado el recorrido para todos. Esto llevó a todos los adultos implicados a reflexionar acerca de las impresiones que pueden dejar las actividades didácticas más allá de las impresiones de una lógica adulta.

En otro grupo, la décima sirvió de insumo posterior para el aula de música, tal como fuera manifestado por el docente de dicha asignatura y que acompañó al grupo y a la docente de historia. Este otro aspecto hace pensar acerca de la importancia y necesidad de la transversalidad e interdisciplinariedad en el abordaje del patrimonio cultural.

En cuanto al tercer y último aspecto observado -la participación-, se evidenció que no fue homogénea a la interna de cada grupo ni en una comparación intra grupos. La construcción colectiva de la décima requirió un esfuerzo intelectual importante porque debía recoger elementos vivenciados, conceptos vertidos en el recorrido y conexiones con lo abordado en el aula escolar. Si bien la participación fue dispar, en ninguno de los trece grupos se observaron elementos disruptivos que impidiesen llegar al producto final esperado.

De los datos obtenidos mediante las tres técnicas utilizadas se puede afirmar que, en líneas generales, no se evidencian diferencias sustanciales entre las décimas provenientes de alumnos de instituciones públicas y de las privadas en lo atinente a la concepción del patrimonio. Sin embargo, se comprueban algunos aspectos disímiles en cuanto a la forma -no tanto en lo referente al contenido. En este sentido es elocuente el léxico empleado 
en una décima de estudiantes de contexto crítico: "Vinimo a ver la muralla, escuchamos a la doña, partiendo desde la playa" (Décima F). Este mismo lenguaje y comportamiento se observó a lo largo del recorrido y en el propio proceso de construcción de la décima.

Más allá de estas disonancias de forma, se podría realizar otra categorización que denotara un desarrollo progresivo en la concepción del patrimonio. Dicha categorización estaría dividida en tres niveles:

mirada natural y "romántica" cargada de emoción sin visualizarse conflictos.

importancia a la puesta en valor del patrimonio y al proceso de selección de los objetos con distinción de elementos identitarios y

construcción colectiva que obedece a los intereses de las diferentes épocas históricas. Los tres niveles mencionados y la distribución de las décimas analizadas de acuerdo al contexto social de procedencia se muestran en el siguiente cuadro:

Cuadro 3. Desarrollo progresivo del concepto de patrimonio

\begin{tabular}{|c|c|c|c|}
\hline NIVELES & $\begin{array}{c}\text { CONCEPCION DEL } \\
\text { PATRIMONIO }\end{array}$ & DÉCIMAS & CONTEXTO SOCIAL \\
\hline $\begin{array}{c}\text { Primer nivel } \\
\text { complejidad y reflexión } \\
\text { sobre el concepto de } \\
\text { patrimonio cultural. }\end{array}$ & $\begin{array}{c}\text { Mirada "romántica". } \\
\text { Visión gloriosa y exenta de } \\
\text { conflictos. } \\
\text { Sobrevaloración de la } \\
\text { emoción. }\end{array}$ & D G M L K & Medio \\
\hline $\begin{array}{c}\text { Nivel intermedio } \\
\text { Se reflexiona acerca de la } \\
\text { necesidad de valoración } \\
\text { del patrimonio }\end{array}$ & $\begin{array}{c}\text { Importancia de la puesta } \\
\text { en valor. } \\
\text { Jerarquización de los } \\
\text { objetos patrimoniales } \\
\text { Identificación de } \\
\text { elementos identitarios. }\end{array}$ & A B C E F H I J & Bático \\
\hline $\begin{array}{c}\text { Tercer nivel } \\
\text { Mayor nivel de } \\
\text { enplejidad y reflexión } \\
\text { objetos patrim de los }\end{array}$ & $\begin{array}{c}\text { Intencionalidad de los } \\
\text { actores en la selección. } \\
\text { Historicidad. } \\
\text { Conflictos de intereses. } \\
\text { Construcción de } \\
\text { ciudadanía crítica. }\end{array}$ & Alto \\
\hline
\end{tabular}

Como se observa, por una parte, la mayoría de las décimas ocho casos de trece- estarían situadas en el segundo nivel de complejidad en el cual se valora la importancia del patrimonio y se vislumbran aspectos identitarios. No obstante, casi un tercio del total se encuentra en el primer nivel de complejidad en el cual se otorga al patrimonio una inmutabilidad cuasi "sacra" exenta de cambios. Por otra parte, ninguna décima se ubica en el tercer nivel de complejidad donde el patrimonio detenta su carácter histórico y dinámico de acuerdo a los intereses de los actores involucrados en cada tiempo y lugar. Si se focaliza la mirada en el contexto social no se advierten diferencias sustanciales en la producción de las décimas con respecto al concepto de patrimonio, destacándose una de ellas en el segundo nivel proveniente de un contexto crítico. 
Al analizar las percepciones de los jóvenes, se puede relacionar -aunque no de forma causal pero sí coadyuvante- la forma en que el patrimonio cultural fue abordado en el contexto del aula. Es decir, cómo se enseña el patrimonio en el contexto escolar, y a su vez de qué manera fueron formados esos docentes.

Mattozzi (2003 en González, 2006) propuso un abordaje del patrimonio estructurado en cuatro etapas de forma gradual, donde cada una de ellas prepara la siguiente. Dichas etapas son:

1. Descubrir que el conocimiento histórico se construye mediante fuentes que constituyen el patrimonio cultural.

2. Descubrir las funciones y las posibilidades del uso del patrimonio más próximo.

3. Experimentar el uso y el valor del patrimonio más próximo.

4. Descubrir el patrimonio cultural en general.

El objetivo principal consistiría en fomentar en el alumnado un grado de comprensión compleja con respecto al entramado que constituye el patrimonio.

\section{Conclusiones}

Comprender qué piensan los jóvenes acerca del patrimonio cultural deviene un desafío para la educación tanto formal como no formal. Pensar el debate acerca de cómo se construye el patrimonio, desde qué lugar se realiza y qué finalidades cumple se torna necesario tanto para el que enseña como para el que aprende.

La idea de dinamismo del patrimonio cultural y del carácter social de su construcción en clave histórica resulta una tarea impostergable para la construcción de una ciudadanía crítica y activa en contextos democráticos. Abordarlo desde esta perspectiva supone un conocimiento de su pasado otorgándole significados para posibilitar una mayor comprensión del presente (González, 2006).

Las percepciones de los jóvenes acerca del patrimonio aquí analizadas son contundentes con respecto a la importancia del mismo en la sociedad. Los jóvenes -con un promedio de edad de 13 años- pueden, de acuerdo al desarrollo psicológico esperado, emplear un pensamiento abstracto para comprender hechos y fenómenos de la realidad. En este sentido, las décimas en general lo demuestran.

Asimismo, la categorización realizada de las trece décimas permitió visualizar los diferentes niveles en la comprensión del patrimonio cultural donde se concibe al patrimonio como un valor que moviliza tanto los aspectos cognitivos como los afectivos. En la mayoría de las producciones estos últimos se vieron potenciados por su estrecha vinculación con la satisfacción de aprender de forma experiencial.

En el segundo nivel de complejidad (Cuadro 3) aparecería un mayor número de décimas, provenientes de estudiantes del sector público. En este sentido, de un total de ocho, cinco son de nivel público y tres del sector privado.

En relación al contexto sociocultural de las instituciones, en este segundo nivel de complejidad están representados los cuatro contextos. Esto, en cierta forma, indicaría que el entorno social del cual provienen los jóvenes no sería una variable explicativa en la conceptualización del patrimonio. Sin embargo, se apreciaron algunas diferencias de riqueza semántica y manejo de vocabulario más afianzado en aquellos jóvenes provenientes de instituciones de nivel medio y alto. 
La guía del docente, la orientación y la impronta que puede brindar en el aprendizaje del patrimonio cultural resultan fundamentales para una cabal comprensión. En una de las trece décimas analizadas, los estudiantes consignaron la voluntad de la docente para que los estudiantes experimentaran un recorrido que les ayudara a comprender el fenómeno. Es importante destacar que los propios estudiantes recuperan este hecho y lo plasman con sus palabras:

"Pa' la profe fue un deseo

vivenciar nuestra historia" (Décima B)

Sobre este aspecto puede pensarse de qué forma la formación de profesores habilitaría el abordaje de una concepción de patrimonio integral y sistémico incursionando más en el valor simbólico e identitario por sobre las dimensiones estética o histórica. (Cuenca López, 2003)

Conocer el patrimonio desde los jóvenes permitió reflexionar acerca de ciudadanos comprometidos con su tiempo y su futuro; acerca de una ciudadanía situada, enfocada a lo local sin olvidar la globalidad, y acercar semejanzas y limar diferencias atendiendo a los conflictos que puedan emerger en el trayecto.

Identificar y comprender las percepciones de los jóvenes permitió adentrarse en el entramado del patrimonio para tejer tramas y destrabar nudos así como también reflexionar acerca de preconceptos y supuestos epistemológicos que impiden desarrollar estrategias adecuadas para el aprendizaje complejo del patrimonio.

\section{Referencia bibliograficas}

Alderoqui, S. (2006). Proas a la ciudad. Ministerio de Educación. Subsecretaría de Educación. Buenos Aires, Dirección General de Educación.

Asensio, M. y Pol, E. (2002). Nuevos escenarios en educación. Aprendizaje informal sobre el patrimonio, los museos y la ciudad ( $1^{\mathrm{a}}$ ed.). Buenos Aires: Aique Grupo Editor.

Ballart, J. y Juan, J. (2010). Gestión del Patrimonio cultural (5a ed). Barcelona: Ariel Patrimonio.

Braudel, F. (1968). La historia y las ciencias sociales. Madrid: Alianza Editorial.

Calvino, I. (2013). Las ciudades invisibles. Buenos Aires: Minotauro.

Carr, E. (1984). Qué es la historia. Barcelona: Ariel.

Cisterna Cabrera, F. (2005). Categorización y triangulación como procesos de validación del conocimiento en investigación cualitativa. Theoria, 14 (1), 61-71. Recuperado de http:// www.redalyc.org/articulo.oa?id=29900107

Cook, T. D. y Reichardt, Ch. S. (1995). Métodos cualitativos y cuantitativos en investigación evaluativa ( $2^{\mathrm{a}}$ ed.). Madrid: Morata.

Corboz, A. (2001). El territorio como palimpsesto. En: Corboz A. (coord.) Le territoire comme palimpseste et autres essais (pp. 15-36) Paris: Besançon.

Corradini, L. (en prensa) "No hay que confundir memoria con historia", dijo Pierre Nora. 
La visión del filósofo y académico francés. La Nación. Recuperado de http://www.lanacion. com.ar/788817-no-hay-que-confundir-memoria-con-historia-dijo-pierre-nora

Cuenca López, J. M. (2003). Análisis de concepciones sobre la enseñanza del patrimonio en la educación obligatoria. Enseñanza de las ciencias sociales, 2003 (2), 37-45.

Delors, J. (1999). La educación encierra un tesoro. Madrid: Santillana - Ediciones Unesco.

Díaz Barriga, F. (2003). Cognición situada y estrategias para el aprendizaje significativo. Revista Electrónica de Investigación Educativa, 5 (2).

Fontal Merillas, O. (2004). La dimensión contemporánea de la cultura. En Calaf R. \& Fontal Merillas, Comunicación educativa del patrimonio: referentes, modelos y ejemplos. Barcelona: Trea.

García Valecillo Z. (2009). ¿Cómo acercar los bienes patrimoniales a los ciudadanos? Educación Patrimonial. Un campo emergente en la gestión del patrimonio cultural. En PASOS. Revista de Turismo y Patrimonio Cultural, 7 (2), 271-280. 2009. Tenerife: Universidad de la Laguna.

Giacomasso et al. (2014). Jóvenes resignificando patrimonios. Análisis de una experiencia escolar en la ciudad de Olavarría en Espacios en Blanco. Serie Indagaciones, 24, Junio 2014, 225-246.

Goetz J. P. y LeCompte, M. D. (2010). Etnografía y diseño cualitativo en investigación educativa. Madrid: Morata.

González Monfort, N. (2006). El valor educativo y el uso didáctico del patrimonio cultural. (Tesis Doctoral) Universitat Autónoma de Barcelona.

Hayden, D. (1997) The power of place. Urban Landscapes as Public History. USA: Asco Trade Typesetting Ltd.

Hernández, F. X. (2003). El patrimonio como recurso en la enseñanza de las ciencias sociales. En Ballesteros, D.- Fernández, C.- Molina, J.A. - Moreno, P. (Coords.). El patrimonio y la didáctica de las ciencias sociales (pp. 455-466). Cuenca: AUPDCS-Universidad de Castilla La Mancha.

Kolb, D. A. (1984). Experiential Learning: Experience as the source of learning and development. New Jersey: Prentice Hall.

Lipovetsky, G. (1996). La era del vacío. Barcelona: Anagrama.

Mançano Fernández, B. (2005). Movimentos socioterritoriais e movimentos socioespaciais. OSAL, Año VI (16), 273-283, CLACSO: Buenos Aires.

Mattozzi, I. (2003). Um bene culturale non fa patrimonio. En González, N. (2006). El valor educativo y el uso didáctico del patrimonio cultural. (Tesis Doctoral) Universitat Autónoma de Barcelona.

Merriam, S. (1998). Qualitative research and case study. Applications in education. San Francisco: Jossey- Bass 
Prats, L. (1997). Antropología y patrimonio. Barcelona: Ariel.

Stake, R. (1999). Investigación con estudio de casos. Madrid: Morata.

Texeira S. en Cantón Arjona, V. (2009). La educación patrimonial como estrategia para la formación ciudadana. En Correo del maestro. Revista para profesores de educación básica. Número 154. Correo del Maestro

Tugores, F. y Planas R. (2006). Introducción al patrimonio cultural. Gijón: Trea.

Unesco (2005). Patrimonio mundial en manos de jóvenes. Conocer, atesorar y actuar Paquete de materiales didácticos para docentes. Paris: UNESCO

Yin, R (2003). Case Study Research. Design and Methods (Applied Social Research Methods) (Third edition). California, Thousand Oaks: Sage Publications 